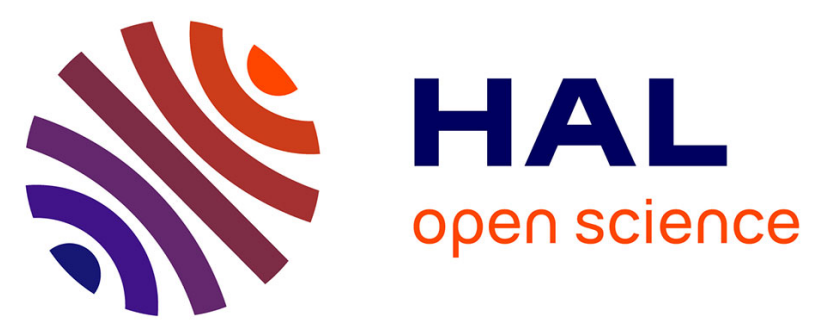

\title{
Serotonin differentially modulates excitatory and inhibitory synaptic inputs to putative sleep-promoting neurons of the ventrolateral preoptic nucleus
} Aude Sangare, Romain Dubourget, Hélène Geoffroy, Thierry Gallopin, Armelle Rancillac

\section{To cite this version:}

Aude Sangare, Romain Dubourget, Hélène Geoffroy, Thierry Gallopin, Armelle Rancillac. Serotonin differentially modulates excitatory and inhibitory synaptic inputs to putative sleep-promoting neurons of the ventrolateral preoptic nucleus. Neuropharmacology, 2016, 109 (1), pp.29-40. 10.1016/j.neuropharm.2016.05.015 . inserm-02121065v2

\section{HAL Id: inserm-02121065 \\ https://www.hal.inserm.fr/inserm-02121065v2}

Submitted on 21 Jun 2021

HAL is a multi-disciplinary open access archive for the deposit and dissemination of scientific research documents, whether they are published or not. The documents may come from teaching and research institutions in France or abroad, or from public or private research centers.
L'archive ouverte pluridisciplinaire HAL, est destinée au dépôt et à la diffusion de documents scientifiques de niveau recherche, publiés ou non, émanant des établissements d'enseignement et de recherche français ou étrangers, des laboratoires publics ou privés.

\section{(ㅇ)(1) 80}

Distributed under a Creative Commons Attribution - NonCommercial - ShareAlikel 4.0 


\section{Serotonin differentially modulates excitatory and inhibitory synaptic inputs to putative sleep-promoting neurons of the ventrolateral preoptic nucleus}

Aude Sangare ${ }^{1,2}$, Romain Dubourget ${ }^{1,2}$, Hélène Geoffroy ${ }^{1,2}$, Thierry Gallopin ${ }^{1,2}$ and Armelle Rancillac ${ }^{1,2 * \dagger}$

${ }^{1}$ Brain Plasticity Unit, ESPCI ParisTech, Paris, France.

${ }^{2}$ Centre National de la Recherche Scientifique, UMR 8249, France.

$\dagger$ Present address: Armelle Rancillac, CIRB, College de France, CNRS UMR 7241 / Inserm U1050

Running title: 5-HT modulation of synaptic inputs in the VLPO.

*Corresponding author: armelle.rancillac@college-de-france

\footnotetext{
Abbreviations:

5-HT, serotonin; 5-HTR, serotonergic receptor; Gal, galanin; mEPSC, miniature excitatory post-synaptic current; mIPSC, miniature inhibitory post-synaptic current; NA, noradrenaline; PSP, putative sleep-promoting neuron; scRT-PCR, single-cell reverse transcription polymerase chain reaction; sEPSC, spontaneous excitatory post-synaptic current; sIPSC, spontaneous inhibitory post-synaptic current; VLPO, ventrolateral preoptic nucleus.
} 
Chemical compounds studied in this article:

Bicuculline (PubChem CID: 104871); kynurinic acid (PubChem CID: 3845); noradrenaline (PubChem CID: 297812); serotonin (PubChem CID: 160436); tetrodotoxin (PubChem CID: 16759596); 8-OH-DPAT (PubChem CID: 6917794); PF03246799 hydrochloride (PubChem CID 67097843).

Keywords: VLPO, single-cell RT-PCR, Gal-GFP neurons, EPSCs, IPSCs, NREM 


\section{Introduction}

The role of serotonin in sleep-wake regulation has been a topic of great scientific debate over the past 60 years. Indeed, deciphering the effects of serotonin (5-hydroxytryptamine, or 5-HT) on sleep is a complex matter, especially since this monoamine neurotransmitter plays major roles in several physiological functions including appetite, gastrointestinal motility, thermoregulation, nociception, emotion and cognition (Artigas, 2015; Berger et al., 2009; Stiedl et al., 2015). Moreover, 5-HT effects are mediated by a wide family of receptors that are classified into seven main receptor subtypes, designated 5- $\mathrm{HT}_{1-7}$. The 5- $\mathrm{HT}_{4}, 5-\mathrm{HT}_{6}$ and 5- $\mathrm{HT}_{7}$ classes presently have one subtype each, whereas the remaining receptor classes are composed of five (5-HT 1 A-B-D-E-F), three $\left(5-\mathrm{HT}_{2 \mathrm{~A}-\mathrm{B}-\mathrm{C}}\right)$ or two $\left(5-\mathrm{HT}_{3 \mathrm{~A}-}\right.$ в and 5-HT5 $5-\mathrm{B})$ receptor subtypes (Hannon and Hoyer, 2008). All 5-HT receptors (5HTR) are G protein-couple receptors with the exception of the ligand ion channel 5$\mathrm{HT}_{3} \mathrm{R}$, and all receptors produce excitatory responses except for types 1 and 5 (Monti, 2011).

The relationship between 5-HT and sleep was first reported in the 1950s, when the decrease in cerebral 5-HT following the administration of reserpine was observed to induce sedation (Brodie et al., 1955). In the following decade, the destruction of serotonergic nuclei, as well as the inhibition of 5-HT synthesis with pchlorophenylalanine, were both shown to induce persistent insomnia, reinforcing the link between 5-HT and sleep induction (Delorme et al., 1966; Jouvet and Renault, 1966). However, in vivo recordings from raphe neurons during sleep-wake cycles have refuted the role of serotonergic neurons in the regulation of non-rapid eye movement (NREM) sleep, since the electrical activity of 5-HT neurons in raphe nuclei decreases in frequency during NREM as compared to wakefulness (Lydic et al., 1987; McGinty and Harper, 
1976; Trulson and Jacobs, 1979). In addition, in vivo microdialysis in cats indicates that the level of 5-HT release in serotonergic dorsal raphe nuclei (DRN) parallels the time course of presumptive serotonergic neuronal activity, which decreases from waking until NREM and continues through rapid eye movement (REM) sleep (Portas and McCarley, 1994).

Hypotheses concerning the serotonergic involvement in sleep-wake regulation are continually evolving, owing to the improvement of technical approaches. In fine, the observation that raphe neurons diminish their firing rates during sleep has been revised, since recordings of atypical neurons in the dorsal raphe nucleus were shown to display the highest discharge frequency during NREM sleep, including a suppression of firing during both wakefulness and REM sleep (Sakai and Crochet, 2001). Moreover, the preoptic area, containing the ventrolateral preoptic area (VLPO), was the only brain region in which small doses of 5-HT precursor microinjections could restore long periods of physiological sleep, when a 5-HT synthesis inhibitor was injected to completely induce insomnia in cats (Denoyer et al., 1989). A better understanding of the mode of action and the effects of 5-HT is therefore fundamental to appreciating the physiological role of 5HT on the behavioral state, in particular within the VLPO. Indeed, this hypothalamic structure is involved in NREM sleep promotion and maintenance by forming reciprocal inhibitory connections with wake-promoting structures (Gallopin et al., 2000; Saper et al., 2001), and it mostly receives serotonergic inputs from innervation by the DRN (Chou et al., 2002).

The VLPO is composed of a small cluster of GABAergic and galaninergic neurons (Chou et al., 2002; Lu et al., 2000; Sherin et al., 1996; Steininger et al., 2001; Szymusiak et al., 1998). The inhibition of these VLPO neurons by wake-promoting neurotransmitters is in 
agreement with their inactivity during wakefulness, and suggests that they should correspond to the sleep-active cells recorded in vivo and that are involved in the inhibition of arousal systems (Saper et al., 2001; Szymusiak et al., 1998). Henceforth, sleeppromoting neurons have been identified according to their inhibitory response to bath application of noradrenaline (NA) (Gallopin et al., 2005, 2000; Liu et al., 2013; Moore et al., 2012; Saint-Mleux et al., 2004; Varin et al., 2015). In contrast to other neurotransmitters that promote wakefulness, 5-HT was shown to induce opposite responses, as revealed by ex vivo electrophysiological recordings of presumed sleeppromoting (PSP) neurons in the rat VLPO. Indeed, neurons inhibited by NA were also inhibited (44\%; Type-1) or excited (56\%; Type-2) by 5-HT, revealing two different neuronal subtypes of PSP neurons (Fort et al., 2009; Gallopin et al., 2005).

In order to better understand the complex regulation of VLPO PSP neuronal excitability by 5 -HT, we performed whole-cell patch-clamp recordings of these neurons in slice preparations of juvenile mice. Neuronal excitability and effects on spontaneous/miniature excitatory and inhibitory postsynaptic currents (EPSCs and IPSCs, respectively) were examined in response to 5-HT application. We also identified electrophysiological, molecular and morphological features of Type-1 vs. Type-2 PSP neurons. These results characterize two different types of neurons within the VLPO that could play distinct roles in sleep regulation. 


\section{Methods}

\subsection{Animals}

Male-only C57BL/6J mice (Charles River, France) and FVB Gal-GFP mice (Mutant Mouse Regional Resource Center (MMRRC), USA), 14 to 18 days old, were used to record the serotonergic modulation of afferent inputs and to perform scRT-PCR, respectively. The Gal-GFP mouse strain STOCK Tg(Gal-EGFP)HX109Gsat/Mmucd (identification number 016342-UCD) was obtained from the MMRRC, a NIH-funded strain repository, and was donated to the MMRRC by the NINDS-funded GENSAT BAC transgenic project. Dr. N. Heintz, the donating investigator of this Gal-GFP mouse strain, was the first to publish it (Gong et al., 2003). All animals were housed in a temperaturecontrolled room $\left(20-22^{\circ} \mathrm{C}\right)$ under a 12-hour light-dark cycle (lights on at 09:00 a.m.) with ad libitum access to food and water. All animal procedures were conducted in strict compliance with our institutional protocols and were approved by the European Community Council Directive of 22 September 2010 (010/63/UE) and the local ethics committee (Comité d'éthique en matière d'expérimentation animale number 59, C2EA59, 'Paris Centre et Sud'). The number of animals in our study was accordingly kept to the necessary minimum.

\subsection{Slice preparation}

Animals were decapitated at the beginning of the light phase, between 09:00 and 10:00 a.m. Brains were quickly extracted without removing the meninges and submerged in cold slicing artificial cerebrospinal fluid (aCSF, $4^{\circ} \mathrm{C}$ ) containing (in $\mathrm{mM}$ ): $130 \mathrm{NaCl}$; $5 \mathrm{KCl} ; 2.4 \mathrm{CaCl}_{2} ; 20 \mathrm{NaHCO}_{3} ; 1.25 \mathrm{KH}_{2} \mathrm{PO}_{4} ; 1.3 \mathrm{MgSO}_{4} ; 10$ D-glucose; 15 sucrose; and 1 kynurenic acid $(\mathrm{pH}=7.35)$. Brains were constantly oxygenated with $95 \% \mathrm{O} 2-$ $5 \% \mathrm{CO}_{2}$. During slicing, $1 \mathrm{mM}$ kynurenate was added to the aCSF. Coronal brain slices 
(300 $\mu \mathrm{m}$ thick) containing the VLPO were cut with a vibratome (VT2000S; Leica) and transferred to a constantly oxygenated $(95 \% \mathrm{O} 2-5 \% \mathrm{CO} 2)$ holding chamber containing aCSF. Subsequently, individual slices were placed in a submerged recording chamber maintained at $32^{\circ} \mathrm{C}$ and perfused $(1.5 \mathrm{~mL} / \mathrm{min})$ with oxygenated kynurenate-free aCSF, and placed under a microscope (Axioscop2FS; Zeiss) for observation.

\subsection{Morphological analysis}

The targeted neurons were located in the VLPO cluster and were photographed prior recording with a CoolSnapHQ2 $\mathrm{CCD}$ camera (CoolSNAP $H Q^{2}$; Roper Scientific) controlled by the Image-Pro 7 software (Media Cybernetics Inc., San Diego, CA). Morphological features were measured from these images after calibration with a standard $24-\mu \mathrm{m}$ grid. In order to describe morphological features of VLPO neurons, 8 parameters related to features of their soma were extracted from infrared pictures taken prior to whole-cell recording in the cell-attached configuration. Their area, perimeter, form factor and maximal (Feret max) and minimal (Feret min) diameters passing through the centroid were computed. The degree of flatness of a contour shape, taken as the ratio of its minimum diameter to its maximum diameter, was indicated as the aspect ratio. The measurement of how closely this shape approached that of a circle was assessed throughout the roundness. Finally, the somatic solidity, the ratio of somata area as a whole over convex area, where values closer to 1 represent more solid (i.e. smooth, uniform) somata was calculated for each soma.

\subsection{Whole-cell patch-clamp recordings}

Slices were maintained immersed and continuously surperfused at $1-2 \mathrm{~mL} / \mathrm{min}$ with oxygenated kynurinic acid-free aCSF. All electrophysiological experiments were 
performed with a MultiClamp700B (Axon Instruments) amplifier connected to an acquisition board (Digidata 1440; Axon Instruments) attached to a computer running the pCLAMP software (Axon Instruments). Fluorescent neurons were observed using a Zeiss filter (GFP: filter set 38, excitation filter 470/40 and emission filter 630/75).

Recordings in the whole-cell patch-clamp configuration were performed with patchclamp pipettes (3-6 M $\Omega$ ) filled with $8 \mu$ l of internal solution containing (in $\mathrm{mM}$ ): $144 \mathrm{~K}$ gluconate; $1 \mathrm{MgCl}_{2} ; \quad 0.5$ EGTA; 10 HEPES (pH 7.2); and 285-295 mOsm. For morphological analysis, $2 \mathrm{mg} / \mathrm{mL}$ biocytin (Sigma Aldrich) was added to the internal solution. This internal solution was chosen to keep the cell as close as possible to physiological conditions, and because sleep-promoting neurons have very short dendrites that limit voltage-gated currents (due to a lack of space clamp). The pipette was slowly brought to the selected neuron for recording in whole-cell configuration using infrared videomicroscopy guidance and clamped at $-60 \mathrm{mV}$. The intrinsic neuronal membrane properties were assessed by applying current steps (800 ms) from $-100 \mathrm{pA}$ until firing saturation, in $10 \mathrm{pA}$ increments.

For each neuron, 11 electrophysiological parameters were measured according to the Petilla terminology (Ascoli et al., 2008), as fully described in (Karagiannis et al., 2009). Briefly, the resting membrane potential was measured immediately after passing to whole-cell configuration. Input resistance $(\mathrm{Rm})$ and the membrane time constant $(\tau \mathrm{m})$ were determined at the beginning of the voltage response of a hyperpolarization current step $(10 \mathrm{pA}, 800 \mathrm{~ms})$. The time constant was determined by fitting this voltage response to a single exponential. Membrane capacitance $(\mathrm{Cm})$ was calculated according to the equation $\mathrm{Cm}=\tau \mathrm{m} / \mathrm{Rm}$. Under our conditions, injection of hyperpolarizing current pulses often induced a hyperpolarization-activated cationic current (Ih) that followed the initial 
hyperpolarization peak, known as a sag. $\mathrm{G}_{\mathrm{sag}}$ was measured as the slope of the linear portion of a current-voltage (I-V) plot, measured at the end of the hyperpolarizing current pulses $(0.7-0.8 \mathrm{~s} ;-100$ to $0 \mathrm{pA})$. $\mathrm{G}_{\text {hyp }}$ was measured as the slope of the linear portion of an $\mathrm{I}-\mathrm{V}$ plot, measured at the beginning $(0-0.1 \mathrm{~s} ;-100$ to $0 \mathrm{pA}) . \Delta \mathrm{GSag}$ corresponds to $\left(\mathrm{G}_{\text {sag }}-\mathrm{G}_{\text {hyp }}\right) / \mathrm{G}_{\mathrm{sag}}$. The amplitude of the first action potential (AP) was measured from the threshold to the positive peak on the first step, where at least 3 APs were induced; AP duration was measured at half-amplitude. The amplitude and the duration of the maximal after-hyperpolarization were measured for the same initial AP. At higher stimulation intensities, the maximal firing rate was defined as the last trace before prominent reduction of the action potential amplitude, indicative of a saturated discharge. Instantaneous firing frequency was fitted to the equation $\mathrm{F}_{\text {sat }}=\mathrm{A}_{\text {sat }} \times \mathrm{E}^{-\mathrm{t} / \tau \mathrm{sat}}+\mathrm{t} \times \mathrm{m}_{\text {sat }}+\mathrm{F}_{\max }$, where $\mathrm{A}_{\text {sat }}$ corresponds to the amplitude of early frequency adaptation, $\tau_{\text {sat }}$ to the time constant of early adaptation, and $m_{\text {sat }}$ to the slope of late adaptation.

Spontaneous and miniature currents were recorded in voltage-clamp mode at a holding potential of $-60 \mathrm{mV}$, which was less negative than the reversal potential for sIPSC. Indeed, the pipette solution contained a low concentration of $\mathrm{Cl}^{-}(1 \mathrm{mM})$, resulting in an $\mathrm{E}_{\mathrm{Cl}}$ of $-111 \mathrm{mV}$. Therefore, inward currents were considered as sEPSCs and outward currents as sIPSCs (Supp. Fig. S1). The broad-spectrum antagonists kynurinic acid (for excitatory events) and bicuculline methiodide (for inhibitory events) respectively inhibited sEPSPs (Fig. 1A and B) and sIPSPs (Supp. Fig. S1C and D), confirming their excitatory and inhibitory roles. Miniature events were recorded by including tetrodotoxin (TTX; $1 \mu \mathrm{M}$ ) in the aCSF. Data were filtered at $2 \mathrm{kHz}$, digitized at $10 \mathrm{kHz}$ and acquired on-line using the pCLAMP 9 (Clampex) software (Axon Instruments). The recorded 
currents were subsequently analyzed using the Mini Analysis program (version 6.0.7; Synaposoft, Inc). The threshold for IPSC and EPSC detection was set at $7 \mathrm{pA}$, and the automatic detection was verified post hoc by visual inspection. A small minority of cells displayed input frequencies greater than $4 \mathrm{~Hz}(n=3 / 58)$, which were outside the range of \pm 2 standard deviations and were thus excluded from the analysis. The ratio of sEPSCs and sIPSCs were calculated, representing the frequency of sEPSCs or SIPSCs $v s$. the frequency of both sIPSCs and sEPSCs.

\subsection{Extracellular recordings in loose cell-attached configuration}

In contrast to whole-cell patch-clamp configuration, extracellular recordings allow stable and long recordings to study the effects of multiple drug application on a single neuron. Gal-GFP neurons were identified by their intrinsic fluorescence and loose cell-attached recordings were made from their stomata with glass capillaries (5-8 M $\Omega$ ). Micropipettes filled with aCSF, were placed in contact with the soma of the selected cell. During these recordings, a seal resistance of $10-15 \mathrm{M} \Omega$ was kept. VLPO neurons were classified as Type- 1 when inhibited by 5-HT, and Type- 2 when excited by 5-HT. We wait at least 10 min between each drug application. 8-OH-DPAT and PF03246799 were alternatively first tested. Only one neuron per slice was recorded. Frequencies were measured over 3 min periods for the baseline, 30 - $60 \mathrm{~s}$ for the drug effect, and $3 \mathrm{~min}, 7$ to $10 \mathrm{~min}$ after the drug application onset for the recovery.

\subsection{Pharmacological studies}

The following drugs were used in the experiments: serotonin hydrochloride (5-HT, $100 \mu \mathrm{M}$; Sigma), noradrenaline (NA, $50 \mu \mathrm{M}$; Sigma), kynurinic acid (2 mM; Sigma), bicuculline methiodide (20 $\mathrm{MM}$; Sigma), tetrodotoxin (TTX; $1 \mu \mathrm{M}$; Latoxan), $( \pm)-8$ - 
Hydroxy-2-(dipropylamino)tetralin hydrobromide (8-OH-DPAT; $1 \mu \mathrm{M}$; Sigma) and PF03246799 hydrochloride (PF03246799; $10 \mu \mathrm{M}$; Sigma).

\subsection{Single-cell reverse transcription polymerase chain reaction ( $s c R T-P C R$ )}

Immediately following patch-clamp recording, the cell's cytoplasm was suctioned into the recording pipette while maintaining a tight seal. Subsequently, the pipette was delicately removed to allow outside-out patch formation. Next, the contents of the pipette were expelled into a test tube and reverse transcription (RT) was performed in a final volume of $10 \mu \mathrm{L}$, as previously described (Vucurovic et al., 2010). This scRT-PCR protocol was designed to simultaneously detect the expression of: the GFP gene used as a reporter of galanin expression; the neuropeptide galanin $(G A L)$; the 2 isoforms of glutamic acid decarboxylase (GAD65 and GAD67); 13 genes encoding for 5-HT receptors $\left(5-H T_{1 A, B, D, F}, 5-H T_{2 A-C}, 5-H T_{3 A}, 5-H T_{4}, 5-H T_{5 A-B}, 5-H T_{6}\right.$ and 5-HT $)$; the enzyme responsible for acetylcholine biosynthesis (ChAT); and the vesicular glutamate transporter type $2(v G L U T 2)$ as a control. The cDNAs present in the RT reaction were first amplified simultaneously by using all of the primer pairs described in Supplementary Table S1. GoTaq G2 DNA polymerase (2.5 U; Promega; Madison, WI, USA) and 20 pmol of each primer were added to the buffer supplied by the manufacturer (final volume: $100 \mu \mathrm{L})$. The thermocycler was programmed for 21 cycles of $94^{\circ} \mathrm{C}(30 \mathrm{~s}), 60^{\circ} \mathrm{C}$ (30 s), and $72^{\circ} \mathrm{C}(35 \mathrm{~s})$. The second round of amplification was performed using $1 \mu \mathrm{L}$ of the first PCR product as template. In the second round, each cDNA was amplified individually with thirty-five PCR cycles, using a second primer pair internal to the pair used in the first PCR (see nested primers in Supp. Table S1). Subsequently, $10 \mu \mathrm{L}$ from each individual PCR product were run on a $2 \%$ agarose gel with a 100-bp ladder (Promega) as a molecular weight marker, and the gel was stained with ethidium bromide. 
Each transcript could be detected from 500 pg of neocortical RNA using this protocol. The sizes of the PCR-generated fragments conformed to the sizes predicted by their mRNA sequences (Supp. Table S1).

\subsection{Statistics}

All data are expressed as the mean \pm standard error of the mean (SEM). 5-HT, 8-OHDPAT and PF03246799 were considered to have an effect on firing rates when the mean frequency changed more than twice the SEM of the control period. Statistical significances between two groups were determined using a Mann-Whitney $U$-test or a Wilcoxon test for unpaired and paired data respectively. The $P$-value given for each analysis is indicated in the results section. $P$ values of $\leq 0.05$ were considered statistically significant. In all cases, $\mathrm{n}$ refers to the number of neurons examined. 


\section{Results}

Here, we investigated how 5-HT operates within the VLPO, using acute hypothalamic slices in mice. In accordance with previous reports, the VLPO PSP neurons were identified by their inhibitory response to bath application of NA ( $50 \mu \mathrm{M}$ for $30 \mathrm{~s})$ and were named as NA (-) neurons, whereas the neighboring neurons were excited by NA application (i.e. NA (+) neurons) (Gallopin et al., 2005, 2000; Liu et al., 2013; Moore et al., 2012). The VLPO neurons were then recorded in whole-cell patch-clamp configuration, and their electrophysiological properties were analyzed in current-clamp mode. 5-HT was bath applied (100 $\mu \mathrm{M}$ for $1 \mathrm{~min})$, and the global membrane current as well as the spontaneous or miniature IPSC and EPSC responses were simultaneously recorded (Supp. Fig. S1).

\subsection{Two types of PSP neurons in the VLPO}

56 PSP neurons were recorded in the VLPO (Figs. 1A and 2A). In these PSP neurons, bath application of 5-HT induced either an outward inhibitory current (Type-1 neurons; $n=19$; Fig. 1B, E and H) or an inward excitatory current (Type-2 neurons; $n=23$; Fig. 2B, E and H). Both effects persisted in the presence of TTX $(1 \mu \mathrm{M} ; n=6$ and $n=8$ respectively; Figs. 1E, H and 2E, H), indicating (at least in part) a postsynaptic effect.

The main membrane properties of Type-1 vs. Type-2 PSP neurons were then compared in current-clamp mode. We found no differences between these two types regarding their membrane resting potential, input resistance, amplitude, and duration of the action potential (AP) and after-hyperpolarization (AHP) (Table 1). Conversely, the action potential threshold was significantly lower in Type-1 vs. Type-2 PSP neurons $(-43.8 \pm 0.8$ 
vs. $-40.9 \pm 0.6 \mathrm{mV} ; P<0.05$; Table 1$)$, whereas $\mathrm{m}_{\text {sat }}$ was significantly higher in Type-1

vs. Type-2 PSP neurons $(-18.1 \pm 3.0$ vs. $-23.9 \pm 2.1 \mathrm{~Hz} / \mathrm{s} ; P<0.05$; Table 1$)$.

Table 1. Electrophysiological membrane properties of Type-1 and Type-2 PSP neurons.

\begin{tabular}{lcc}
\hline & Type-1 $(n=25)$ & Type-2 $(n=31)$ \\
\hline $\mathbf{R M P}(\mathrm{mV})$ & $-44.0 \pm 1.3$ & $-42.6 \pm 1.2$ \\
$\mathbf{I R}(\mathrm{M} \Omega)$ & $885.7 \pm 110.9$ & $895.5 \pm 84.6$ \\
$\mathbf{C m}(\mathrm{pF})$ & $52.9 \pm 5.0$ & $51.9 \pm 4.5$ \\
$\boldsymbol{\tau}_{\text {th }}(\mathrm{ms})$ & $41.0 \pm 4.5$ & $41.8 \pm 4.2$ \\
$\Delta \mathbf{G s a g}(\%)$ & $70.0 \pm 4.0$ & $73.4 \pm 3.7$ \\
$\mathbf{A}_{\text {sat }}(\mathrm{Hz})$ & $73.0 \pm 6.7$ & $63.0 \pm 5.3$ \\
$\boldsymbol{\tau}_{\text {sat }}(\mathrm{ms})$ & $28.8 \pm 3.1$ & $27.2 \pm 5.2$ \\
$\mathbf{m}_{\text {sat }}(\mathrm{Hz} / \mathrm{s})$ & $-23.9 \pm 2.1 *$ & $-18.1 \pm 3.0$ \\
$\mathbf{C}_{\text {sat }}(\mathrm{Hz})$ & $49.8 \pm 2.7$ & $52.3 \pm 4.5$ \\
$\mathbf{A P}_{\text {threshold }}(\mathrm{mV})$ & $-43.8 \pm 0.8 *$ & $-40.9 \pm 0.6$ \\
$\mathbf{A P}_{\text {ampl }}(\mathrm{mV})$ & $88.8 \pm 2.9$ & $89.2 \pm 2.1$ \\
$\mathbf{A P}_{\text {half }}$ width $(\mathrm{ms})$ & $1.0 \pm 0.0$ & $1.1 \pm 0.0$ \\
$\mathbf{A H P}_{\text {ampl }}(\mathrm{mV})$ & $-9.2 \pm 1.3$ & $-7.4 \pm 0.8$ \\
$\mathbf{A H P}_{\text {width }}(\mathrm{ms})$ & $115.8 \pm 13.8$ & $97.1 \pm 14.3$ \\
\hline
\end{tabular}

Abbreviations: RMP: resting membrane potential; IR: input resistance; $\mathrm{Cm}$ : membrane capacity; $\tau_{\text {th }}$ : membrane time constant at threshold; $\Delta$ Gsag: the percentage difference between the peak amplitude of the initial response relative to the peak amplitude of the steady state response. $\mathrm{A}_{\text {sat: }}$ corresponds to the amplitude of early frequency adaptation at the maximal firing rate; $\tau_{\text {sat }}$ membrane time constant of early adaptation; $\mathrm{m}_{\text {sat: }}$ corresponds to the slope of late adaptation; AP: action potential; AHP: afterhyperpolarization. Data are presented as mean \pm SEM. Significant differences are highlighted in gray. ${ }^{*} P \leq 0.05$; Mann-Whitney $U$-test.

These results suggest that Type- 1 neurons are more excitable than Type- 2 neurons. However, Type-2 PSP neurons displayed a higher $\mathrm{m}_{\text {sat }}$, indicating that they can fire continuously in a more sustained, high-frequency discharge than Type-1 neurons. Therefore, some electrophysiological properties can be used to discriminate between these two different types of PSP neurons, in addition to their serotonergic response.

Infrared microphotography measurements of the recorded cells (Figs. 1A and 2A) revealed that Type-1 and Type-2 PSP neurons present similar morphological somatic 
hallmarks (Table 2). The one exception was that the area of Type-1 PSP neurons was significantly smaller as compared to Type-2 neurons $\left(127.4 \pm 6.5 \mu \mathrm{m}^{2} v s\right.$. $160.3 \pm 10.6 \mu \mathrm{m}^{2} ; P \leq 0.05$, Mann-Whitney $U$-test; Table 2).

Table 2. Somatic properties of Type-1 and Type-2 PSP neurons within the VLPO

\begin{tabular}{lcc}
\hline & Type-1 $(n=25)$ & Type-2 $(n=31)$ \\
\hline Area $\left(\mu \mathrm{m}^{2}\right)$ & $126.8 \pm 6.7 *$ & $160.3 \pm 10.6$ \\
Perimeter $(\mu \mathrm{m})$ & $44.5 \pm 1.1$ & $50.4 \pm 2.0$ \\
Form factor & $0.8 \pm 0.0$ & $0.8 \pm 0.0$ \\
Feret max $(\mu \mathrm{m})$ & $16.9 \pm 0.5$ & $19.4 \pm 1.0$ \\
Feret min $(\mu \mathrm{m})$ & $10.1 \pm 0.4$ & $11.1 \pm 0.3$ \\
Aspect ratio & $1.8 \pm 0.1$ & $1.8 \pm 0.1$ \\
Roundness & $0.6 \pm 0.0$ & $0.6 \pm 0.0$ \\
Solidity & $1.0 \pm 0.0$ & $1.0 \pm 0.0$ \\
\hline
\end{tabular}

Data are presented as mean \pm SEM. Significant differences are highlighted in gray. $* P \leq 0.05$; Mann-Whitney $U$-test.

3.2. 5-HT presynaptically inhibits glutamatergic and GABAergic inputs to Type-1 PSP neurons

To determine how 5-HT $(100 \mu \mathrm{M}$ for $1 \mathrm{~min})$ modulates afferent glutamatergic and GABAergic inputs to PSP neurons, spontaneous and miniature EPSCs and sIPSCs were simultaneously recorded in voltage-clamp configuration. 5-HT did not significantly change sEPSC amplitude in Type-1 PSP neurons, but it did significantly reduce the frequency of sEPSCs from $0.9 \pm 0.1$ to $0.5 \pm 0.1 \mathrm{~Hz}(n=19 ; P<0.001$, Wilcoxon test; Fig. 1B and C), suggesting a serotonergic modulation of excitatory inputs via a presynaptic mechanism.

No sIPSCs were observed in 11 out of 19 Type-1 neurons, indicating that 5-HT significantly reduced the mean sIPSC amplitude in the remaining Type-1 neurons $(15.6 \pm 1.0 v s .12 .9 \pm 0.9 \mathrm{pA}, n=8 ; P=0.008$, Wilcoxon test $)$ and significantly reduced 
their mean frequency $(0.11 \pm 0.03$ vs. $0.06 \pm 0.02 \mathrm{~Hz}, n=8 ; P=0.039$, Wilcoxon test; Fig. 1B and D). These results suggest a serotonergic modulation of inhibitory inputs via both presynaptic and postsynaptic mechanisms.

Spontaneous postsynaptic currents (sPSC) can be generated by the action potentialdependent release of neurotransmitters due to the firing of neighboring neurons in the slice, or they can be generated by spontaneous action potential-independent release from the synaptic terminal. To assess whether 5-HT could act directly on the presynaptic terminals, we recorded action potential-independent postsynaptic currents referred to as miniature EPSCs and IPSCs (mEPSCs and mIPSCs, respectively) after pre-incubation in tetrodotoxin (TTX, $1 \mu \mathrm{M}$ ) for $5 \mathrm{~min}$, prior to the application of 5-HT. We found that in the presence of TTX, 5-HT significantly decreased the frequency of mEPSCs in Type-1 neurons $(0.57 \pm 0.28$ vs. $0.42 \pm 0.23 \mathrm{~Hz} ; n=7 ; P=0.016$, Wilcoxon test $)$, but not their amplitude ( $21.01 \pm 4.25$ vs. $17.92 \pm 3.10 \mathrm{pA}, n=7 ; P=0.078$, Wilcoxon test, Fig. 1F). We also observed a significant decrease in mIPSC frequency $(0.21 \pm 0.06$ to $0.15 \pm 0.05 \mathrm{~Hz} ; n=6 ; P=0.031$, Wilcoxon test) and amplitude (12.21 \pm 1.64 to $10.59 \pm 1.55 \mathrm{pA} ; n=6 ; P=0.031$, Wilcoxon test; Fig. $1 \mathrm{G})$

Altogether, these results indicate that in the VLPO, 5-HT inhibits glutamatergic excitatory inputs to Type-1 neurons via a presynaptic mechanism, since sEPSC and mEPSC frequencies are significantly reduced following 5-HT bath application. In addition, the decrease in sIPSC and mIPSC amplitude revealed a postsynaptic 5-HT effect. Indeed, the 5-HT-mediated hyperpolarization of Type-1 PSP neurons brings the membrane potential closer to $\mathrm{E}_{\mathrm{Cl}}$, thereby decreasing the amplitude of IPSCs.

Furthermore, the ratio of sIPSCs was significantly lower than the ratio of mIPSCs in the presence of 5-HT $(0.07 \pm 0.09 v s .0 .43 \pm 0.16, P=0.05$, Mann-Whitney $U$-test; Fig. 1I). 
This suggests for Type-1 PSP neurons that local neurons should repress inhibitory events and contribute to the observed decrease in transmitter release from presynaptic terminals.

\subsection{5-HT presynaptically enhances the GABAergic inputs to PSP Type-2 neurons}

5-HT application did not alter the frequency or the amplitude of sEPSCs in 23 Type-2 PSP neurons (Fig. 2B and C). In contrast, 5-HT induced a significant increase in sIPSC frequency, from $0.15 \pm 0.07$ to $0.6 \pm 0.29 \mathrm{~Hz}(n=10 ; P<0.05$, Wilcoxon test; Fig. 2D), with no observed change in their sIPSC amplitude (Fig. 2B and D). No sIPSCs were detected in 57\% (13/23) of Type-2 PSP neurons.

We next examined the possibility of a direct role of 5-HT on glutamatergic and GABAergic terminals, by recording its effect on mEPSCs and mIPSCs. This revealed that 5-HT significantly affected the frequency of inhibitory events in PSP Type-2 neurons, from $0.03 \pm 0.01$ to $0.11 \pm 0.04 \mathrm{~Hz}(n=6 ; P=0.031$, Wilcoxon test, Fig. $2 \mathrm{E}-\mathrm{G})$.

Furthermore, the ratio of sIPSCs was not significantly different than the ratio of mIPSCs $(0.19 \pm 0.12$ vs. $0.13 \pm 0.07, P=0.936$, Mann-Whitney $U$-test; Fig. 2I $)$ in the presence of 5-HT. This result suggests that local neurons are not involved in the modulation of synaptic inputs to Type-2 PSP neurons.

\subsection{Molecular diversity of 5-HT receptors}

Following the electrophysiological characterization, we investigated the molecular diversity of PSP neurons using the scRT-PCR technique. Since RNA transcripts in individual cells of living brain slices are fragile and likely degraded during whole-cell patch-clamp recordings, it is necessary to optimize the RNA transcript levels. For this, 
we rapidly harvested the cell cytoplasm after the patch breakdown (which also prevented any long pharmacological characterization of the neurons). Transgenic mice expressing GFP under the transcriptional control of the galanin gene (Gal-GFP mice) were used to facilitate identification of PSP neurons in the VLPO, based on their fluorescence (Fig. 3A). Indeed, galanin is the only known reliable chemical marker of PSP neurons in the VLPO (Gallopin et al., 2005; Gaus et al., 2002; Lu et al., 2002; Sherin et al., 1998). In a separate set of experiments, all Gal-GFP neurons were hyperpolarized by NA application $(50 \mu \mathrm{M}$ for $20 \mathrm{~s} ; n=14 / 14)$ and located in a dense core within a fluorescent cluster of neurons (Fig. 3B).

We recorded 28 Gal-GFP neurons and utilized an scRT-PCR protocol designed to simultaneously detect the expression of 19 mRNAs encoding: GFP, the neuropeptide galanin $(G A L)$, the 2 isoforms of glutamic acid decarboxylase (GAD65 and GAD67) and 13 5-HT receptors $\left(5-H T_{1 A, B, D, F}, 5-H T_{2 A-C}, 5-H T_{3 A}, 5-H T_{4}, 5-H T_{5 A-B}, 5-H T_{6}\right.$ and 5-HT $)$. We also examined the presence of mRNAs coding for $v G L U T 2$ and ChAT as two control markers of glutamatergic neurons, as well as neighboring cholinergic neurons from the adjacent areas of the basal forebrain (Gritti et al., 1993). The scRT-PCR results of 13 neurons that could amplify at least one GAD mRNA in addition to galanin and/or GFP were retained.

The mRNAs that encode the $5-H T_{3 A}, 5-H T_{5 B}$ and $5-H T_{6}$ receptors were never detected in our sample of Gal-GFP neurons. Furthermore, 5-HT receptor mRNA was only detected in Type-1 neurons, whereas mRNAs encoding 5-HT $2 A-C, 5-H T_{4}$ and $5-H T_{7}$ were equally distributed between Type- 1 and Type-2 Gal-GFP neurons. 5-HT $2 C$ was the most highly expressed receptor, and was detected in $77 \%$ of the VLPO neurons ( $n=10 / 13$, Fig. 3D). 
To determine if the expression pattern of mRNAs encoding 5-HT receptors could be specific for Gal-GFP neurons, we also performed scRT-PCR on non-fluorescent neurons within the VLPO, as previously used with fluorescent neurons. Out of 28 harvested neurons, we only retained the scRT-PCR results of 9 non-fluorescent neurons that could amplify at least one mRNA, and in which the galanin and GFP mRNAs were absent (Supp. Fig. S4). This set of experiments revealed that mRNAs encoding GAD67 or the 5- $H T_{3 A}, 5-H T_{5 B}$ and $5-H T_{6}$ receptors were not detectable within this sample, as was the case for the Gal-GFP neurons. Interestingly, mRNAs encoding $5-H T_{1 A, B, D, F}$ and $5-H T_{2 B}$ receptors that were frequently expressed by fluorescent neurons were not detected in nonfluorescent neurons, suggesting that these receptors could be specific to sleep-promoting neurons. Additionally, we found that half of these non-GFP cells expressed GAD65 $(n=5 / 9)$, whereas vGluT2 mRNA was expressed in the remaining cells $(n=2 / 4)$. This result suggests that these non-Galaninergic cells could correspond to inhibitory or excitatory neurons. This segregation also indicates that the $5-H T_{2 C}$ receptor could be selectively expressed by non-fluorescent glutamatergic neurons, whereas non-fluorescent GABAergic neurons express 5- $\mathrm{HT}_{2 A}, 5-\mathrm{HT}_{4}, 5-\mathrm{HT}_{5 A}$ and 5- $\mathrm{HT}_{7}$ receptors (Supp. Fig. S4). Finally, we analyzed the main properties of Type- 1 and Type-2 Gal-GFP neurons, in order to determine whether they display any electrophysiological and molecular differences from what was previously identified in PSP of C57B16 mice. No significant differences between Type-1 and Type-2 Gal-GFP neurons were found (Supp. Table S2 and S3), indicating that the discrepancy among PSP neurons could be due to the lower number of Gal-GFP recorded neurons as compared to PSP NA (-) neurons, or to differences in the genetic background between C57Bl6 and FVB Gal-GFP mice. Gal-GFP neurons could also define a subpopulation within NA (-) neurons in the VLPO. Indeed, PSP NA (-) neurons were mainly composed of Type-2 neurons, whereas Gal-GFP expressing neurons 
were essentially Type-1 neurons (40/60 vs. 70/30). sEPSCs recorded from Type-1 and Type-2 neurons were significantly more frequent in Gal-GFP vs. PSP neurons $(2.64 \pm 0.59$ vs. $0.91 \pm 0.12 ; P<0.01$ and $1.80 \pm 0.45$ vs. $1.06 \pm 0.25 ; P<0.05$ respectively; Supp. Fig. S2). The input resistance of Gal-GFP was significantly higher as compared to PSP neurons, particularly in Type-1 neurons $(1170.3 \pm 140.4$ vs. 776.2 $\pm 72.7 \mathrm{M} \Omega ; P<0.01 ;$ Mann-Whitney $U$-test).

3.5. Type-1 and Type-2 neurons differentially respond to 5-HT $T_{1 A}$ and 5-HT $T_{1 C}$ receptor agonists

To assess the molecular expression of mRNA encoding for the 5- $\mathrm{HT}_{1 \mathrm{~A}}$ and the $5-\mathrm{HT}_{1 \mathrm{C}}$ receptors, the most expressed serotonergic receptor by Gal-GFP neurons (Fig. 3D), we bath applied their agonists on identified Type- 1 and Type- 2 neurons. Extracellular recordings in loose cell-attached configuration were used to study the effect of multiple drug application on a single VLPO neuron. We used 8-OH-DPAT, a selective 5-HT 1 agonist with high affinity for subtype 5- $\mathrm{HT}_{1 \mathrm{~A}}$ receptor and $\mathrm{PF} 03246799$, a potent 5-HT2C receptor agonist with a minimal activity at $5-\mathrm{HT}_{2 \mathrm{~A}}$ and $5-\mathrm{HT}_{2 \mathrm{~B}}$ receptors. As shown in figure 4, 8-OH-DPAT ( $1 \mu \mathrm{M}, 20 \mathrm{~s})$ strongly and specifically decreased the firing rate of Type-1 neurons $(-83.86 \pm 8.61 \% ; n=6 / 7 ; P<0.031$; Wilcoxon test), whereas no effect was observed on Type-2 neurons (- $7.00 \pm 9.64 \% ; n=7 / 7 ; P<0.375$; Wilcoxon test). In contrast, PF03246799 $(10 \mu \mathrm{M}, 20 \mathrm{~s})$ significantly increased the firing rate of Type-2 neurons (254.54 $\pm 112.29 \% ; n=6 / 7 ; P<0.031$; Wilcoxon test). Interestingly, a weak effect of PF03246799 was also observed in some Type-1 neurons, although their mean increase in firing rate was not statistically significant $(20.21 \pm 5.90 ; n=5 / 7 ; P>0.297$; Wilcoxon test; Fig. 4A and C). 
These results thus reveal that VLPO neurons are responsive to 5-HT via postsynaptic activation of multiple receptor subtypes. The excitatory response to 5-HT is at least partly mediated by $5-\mathrm{HT}_{2 \mathrm{C}}$ receptors, whereas the inhibitory response to serotonin relies on 5$\mathrm{HT}_{1 \mathrm{~A}}$ receptor activation. 


\section{Discussion}

The present study utilized whole-cell patch-clamp recordings in mouse brain slices to investigate how bath application of 5-HT influences afferent inputs to VLPO sleeppromoting neurons. Our results demonstrate that 5-HT hyperpolarizes Type-1 neurons and reduces the frequency of their afferent glutamatergic and GABAergic inputs. The amplitude of their inhibitory inputs was also reduced. In contrast, 5-HT depolarized Type2 neurons and selectively increased the frequency of their afferent inhibitory inputs. Afferent serotonergic inputs to the VLPO that originate from divers nuclei (Chou et al., 2003, 2002; Greco et al., 2008) could therefore differentially target and modulate Type1 and Type-2 neurons to promote sleep.

In line with our results, one previous study on galanin-positive neurons of the VLPO found that the frequency of their mIPSCs ranged from 0.22 to $1.2 \mathrm{~Hz}$, in the control condition (Chamberlin et al., 2003). Nevertheless, the low frequency of inhibitory events likely biased the amplitude measurement due to its small sample size in the relevant time window, and could have masked a serotonergic effect on the IPSC amplitudes of Type-2 neurons. Indeed, the IPSC amplitude depends on the neuronal membrane potential, and here we have demonstrated that a direct serotonergic effect depolarizes these neurons. These IPSCs are farthest from the chloride reversal potential $\left(\mathrm{E}_{\mathrm{Cl}}=-111 \mathrm{mV}\right)$, and we therefore expected a significant increase in IPSC amplitude in response to 5-HT application on Type-2 neurons.

The dual effect of 5-HT on PSP neurons was further investigated using scRT-PCR, in order to identify the 5-HT receptor subtypes that could be responsible for the excitatory or inhibitory effects. Our results indicate that Type- 1 and Type-2 Gal-GFP neurons and non-fluorescent neurons within the VLPO express 3 different sets of mRNAs. Type-1 
neurons express mRNAs that encode $5-\mathrm{HT}_{1 \mathrm{~A}}$ receptors in particular; these receptors likely mediate the hyperpolarizing effect of 5-HT, similar to what has been reported for many other brain regions (Cheng et al., 1998; Hajós et al., 2003; Johnston et al., 2014). In addition, these neurons express mRNAs for the 5- $\mathrm{HT}_{1 \mathrm{~B}, \mathrm{D}, \mathrm{F}}$ and $5-\mathrm{HT}_{5 \mathrm{~A}}$ receptors, which could participate in the inhibitory response toward 5-HT application, since these receptors are negatively coupled to cAMP levels via the Gi/Go protein (Francken et al., 1998; Lin et al., 2002). Type-1 neurons were also observed to express mRNA coding for 5-HT receptors that produce excitatory responses, including $5-\mathrm{HT}_{2 \mathrm{~A}-\mathrm{C}}, 5-\mathrm{HT}_{4}$ and $5-\mathrm{HT}_{7}$ receptors. If these mRNA transcripts are indeed translated into proteins, we hypothesize that a more specific and physiological serotonergic modulation of Type-1 neuronal activity could induce their activation.

Type-2 neurons display a similar molecular profile as Type-1, except for the $5-\mathrm{HT}_{1}$ receptor subtype, which was never detected. Non-fluorescent GABAergic neurons only express mRNAs encoding the $5-\mathrm{HT}_{2 \mathrm{~A}}, 5-\mathrm{HT}_{4}, 5-\mathrm{HT}_{5 \mathrm{~A}}$ and $5-\mathrm{HT}_{7}$ receptors. Therefore, it appears that within the GABAergic population of the VLPO neurons, the 5- $\mathrm{HT}_{2 \mathrm{~B}}$ and 5$\mathrm{HT}_{2 \mathrm{C}}$ receptors appeared to eould be specifically expressed by sleep-promoting neurons to promote mediate sleep in response to 5-HT. Accordingly, Indeed, previous studies have demonstrated that $5-\mathrm{HT}_{2 \mathrm{~A}}$ and the blockade of the $5-\mathrm{HT}_{2 \mathrm{~B}}$ receptor and the lack of 5-HT $2 \mathrm{C}$ receptor in knock-out mice have a significantly reduced in NREM sleep amount (Frank et al., 2002; Kantor et al., 2004).

Regulation of GAD67 expression is well known to differs from those of GAD65 isoform (Buddhala et al., 2009; Soghomonian and Martin, 1998), GAD67 being particularly plastic depending on experimental manipulations (Volk et al., 2000). However, we surprisingly found that mRNA encoding the GAD65 was systematically detected in our 
sample of Gal-GFP neurons, whereas the mRNA encoding the GAD67 was never amplified. Control experiments were performed for all primers to assess their efficiency on cDNA synthesized from mice total RNA. Therefore, the absence of GAD67 mRNA detection did not resulted from a defect in our primer design. Nevertheless, GAD67 mRNA level could have been too low to be properly harvest and amplified. Therefore, our scRT-PCR results suggest that GAD67 is not expressed in VLPO neurons, although we cannot exclude that our experimental conditions were not favorable to their detection. The functional roles of the two GADs still remain incompletely understood. GAD65 and GAD67 were functionally hypostatized to differ in their contributions to the synaptic and nonsynaptic pools of GABA. The GABA generated by GAD67 is believe to be utilized for purposes other than neurotransmission such as trophic functions for synaptogenesis during early development, neuroprotection after neuronal injury and regulator of redox potential during oxidative stress (Lamigeon et al., 2001; Pinal and Tobin, 1998; Waagepetersen et al., 1999). Therefore, it could be interesting to investigate if GAD67 mRNA could be detected in the VLPO earlier in the development.

To confirm the putative expression of $5-\mathrm{HT}_{1 \mathrm{~A}}$ and $5-\mathrm{HT}_{2} \mathrm{C}$ receptors that were the most frequently amplified mRNA by scRT-PCR, we applied potent agonist of these receptors on Gal-GFP VLPO neurons and recorded in loose-patch configuration the modulation of their firing frequency. We established that the selective $5-\mathrm{HT}_{1 \mathrm{~A}}$ receptor agonist $8-\mathrm{OH}-$ DPAT effectively decreased the firing frequency of Type- 1 neurons, whereas a $5-\mathrm{HT}_{2 \mathrm{C}}$ receptors agonist, PF03246799 enhanced the firing frequency of Type-2 neurons.

Interestingly, we also observed that the decreased firing rate induced by 5-HT application in Type-1 neurons was followed by a small increased of their firing rate and that PF03246799 application could also increase the firing rate in a subset of Type-1 neurons. 
Altogether, these results are in good agreements with our scRT-PCR results, indicating that Type-1 neurons express both 5-HT $\mathrm{H}_{1 \mathrm{~A}}$ and $5-\mathrm{HT}_{2 \mathrm{C}}$ receptors. The opposite responses meditated by these receptors displayed distinct kinetics. The $5-\mathrm{HT}_{1 \mathrm{~A}}$ receptor activation mediating an inhibitory effect prior the excitatory effect induced by the activation of 5$\mathrm{HT}_{2 \mathrm{C}}$ receptors. Physiologically, we hypothesize that afferent serotonergic inputs to the VLPO could exert a complex and fine control of sleep-promoting neurons. Nevertheless, it appears from the literature that systemic injections of a 5-HT agonist could produced opposite effects on sleep amounts, depending on the concentration used and on the time of the sleep-wake cycle during which the treatment was administered (Imeri et al., 2005, 1999; Morrow et al., 2008). These studies suggest a circadian modulations of serotonergic receptor function.

The global excitatory effect of serotonin on Type-2 VLPO neurons described in this study strengthens many previous results that have demonstrated the involvement of 5-HT in NREM sleep genesis (Brodie et al., 1955; Delorme et al., 1966; Jouvet and Renault, 1966; Jouvet, 1999; Python et al., 2001). Nevertheless, the inhibitory effect of 5-HT on Type-1 neurons remains to be explained. Similarly, it must still be determined whether the sole role of Type-2 neurons is to promote NREM sleep. Indeed, Type-2 neurons in the VLPO have been shown to selectively respond to an $A_{2 A}$ adenosine receptor agonist (Gallopin et al., 2005; Scharbarg et al., 2016). Thus, they could likely integrate the homeostatic drive that is associated with adenosine accumulation, and first respond to the serotonergic excitatory inputs to promote sleep. Then, the activation of Type- 2 neurons would decrease the frequency of GABAergic inputs to Type-1 neurons to favor their activation. Type-1 
VLPO neurons would then inhibit arousal systems and allow the maintenance of NREM sleep.

However, sleep-promoting neurons are not all gathered within the core of the VLPO. The medial-extended and the dorsal-extended VLPO also contained sleep-promoting neurons that differentially project to the tuberomammillary nucleus or to the dorsal and medial raphe nuclei respectively (Bjorkum et al., 1999; Sherin et al., 1998), suggesting a complex regulation of sleep orchestrated by distinct subpopulations that are spatially organized in the VLPO. Furthermore, the median preoptic nucleus (MnPO) also contains sleep-active neurons that display similar anatomical, physiological and neurochimical properties than VLPO neurons (Gong et al., 2004, 2000; Sherin et al., 1998, 1996; Uschakov et al., 2006). Both structures from a gamma-aminobutyric acid (GABA) - and galaninergic network promoting sleep (Alam et al., 2014; Valatx, 1996).

\subsection{Conclusions}

We have characterized in mice two distinct PSP neuronal populations within the VLPO that respond differentially to 5-HT and express unique sets of mRNAs that encode different 5-HT receptor subtypes. Our results demonstrate a target-specific action of 5HT on individual terminals of Type-1 vs. Type-2 neurons. We therefore hypothesize that Type-2 neurons could be involved in the preparation and initiation of sleep (permissive neurons), whereas Type-1 neurons are likely responsible for sleep maintenance (executive neurons). 


\section{Conflict of interest statement}

We declare no conflict of interest.

\section{Author contributions}

T.G. and A.R. designed the study. A.S., R.D., H.G. and A.R. performed the experiments, analysis and interpretation of data. A.R. supervised, coordinated research activities and wrote the manuscript. T.G. provided critical review of the manuscript. All authors have agreed on the final version of the manuscript.

\section{Acknowledgments}

We thank the Mutant Mice Regional Resource Center for providing the Gal-GFP mice. This work was supported by the French National Center for Scientific Research (CNRS), ESPCI ParisTech, and the French Institute of Health and Medical Research (Inserm). The authors thank Brandon Loveall of Improvence for English proofreading of the manuscript. 


\section{References}

Alam, M.A., Kumar, S., McGinty, D., Alam, M.N., Szymusiak, R., 2014. Neuronal activity in the preoptic hypothalamus during sleep deprivation and recovery sleep. $\mathrm{J}$. Neurophysiol. 111, 287-99.

Artigas, F., 2015. Developments in the field of antidepressants, where do we go now? Eur. Neuropsychopharmacol. 25, 657-670.

Ascoli, G.A., Onso-Nanclares, L., Anderson, S.A., Barrionuevo, G., Avides-Piccione, R., Burkhalter, A., Buzsaki, G., Cauli, B., DeFelipe, J., Fairen, A., Feldmeyer, D., Fishell, G., Fregnac, Y., Freund, T.F., Gardner, D., Gardner, E.P., Goldberg, J.H., Helmstaedter, M., Hestrin, S., Karube, F., Kisvarday, Z.F., Lambolez, B., Lewis, D.A., Marin, O., Markram, H., Munoz, A., Packer, A., Petersen, C.C., Rockland, K.S., Rossier, J., Rudy, B., Somogyi, P., Staiger, J.F., Tamas, G., Thomson, A.M., Toledo-Rodriguez, M., Wang, Y., West, D.C., Yuste, R., 2008. Petilla terminology: nomenclature of features of GABAergic interneurons of the cerebral cortex. Nat. Rev. Neurosci. 9, 557-568.

Berger, M., Gray, J.A., Roth, B.L., 2009. The expanded biology of serotonin. Annu. Rev. Med. 60, 355-366.

Bjorkum, A., Ha, Q., Saper, C., 1999. Afferents to and efferents from the raphe nuclei to the ventrolateral preoptic nucleus. Soc Neurosci Abstr 25:625.

Brodie, B.B., Pletscher, A., Shore, P.A., 1955. Evidence That Serotonin Has a Role in Brain Function. Science (80-. ). 122, 968-968.

Buddhala, C., Hsu, C.-C., Wu, J.-Y., 2009. A novel mechanism for GABA synthesis and packaging into synaptic vesicles. Neurochem. Int. 55, 9-12.

Chamberlin, N.L., Arrigoni, E., Chou, T.C., Scammell, T.E., Greene, R.W., Saper, C.B., 2003. Effects of adenosine on GABAergic synaptic inputs to identified ventrolateral preoptic neurons. Neuroscience 119, 913-918.

Cheng, L.L., Wang, S.J., Gean, P.W., 1998. Serotonin depresses excitatory synaptic transmission and depolarization-evoked $\mathrm{Ca} 2+$ influx in rat basolateral amygdala via 
5-HT(1A) receptors. Eur. J. Neurosci. 10, 2163-2172.

Chou, T.C., Bjorkum, A.A., Gaus, S.E., Lu, J., Scammell, T.E., Saper, C.B., 2002. Afferents to the ventrolateral preoptic nucleus. J. Neurosci. 22, 977-990.

Chou, T.C., Scammell, T.E., Gooley, J.J., Gaus, S.E., Saper, C.B., Lu, J., 2003. Critical role of dorsomedial hypothalamic nucleus in a wide range of behavioral circadian rhythms. J. Neurosci. 23, 10691-10702.

Delorme, F., Froment, J.L., Jouvet, M., 1966. Suppression of sleep with pchloromethamphetamine and p-chlorophenylalanine. C.R.Seances Soc Biol.Fil. 160, 2347-2351.

Denoyer, M., Sallanon, M., Kitahama, K., Aubert, C., Jouvet, M., 1989. Reversibility of para-chlorophenylalanine-induced insomnia by intrahypothalamic microinjection of L-5-hydroxytryptophan. Neuroscience.

Fort, P., Bassetti, C.L., Luppi, P.H., 2009. Alternating vigilance states: New insights regarding neuronal networks and mechanisms. Eur. J. Neurosci. 29, 1741-1753.

Francken, B.J.B., Jurzak, M., Vanhauwe, J.F.M., Luyten, W.H.M.L., Leysen, J.E., 1998. The human 5-ht $(5 \mathrm{~A})$ receptor couples to $\mathrm{G}(\mathrm{i}) / \mathrm{G}(\mathrm{o})$ proteins and inhibits adenylate cyclase in HEK 293 cells. Eur. J. Pharmacol. 361, 299-309.

Frank, M.G., Stryker, M.P., Tecott, L.H., 2002. Sleep and sleep homeostasis in mice lacking the 5-HT2c receptor. Neuropsychopharmacology 27, 869-873.

Gallopin, T., Fort, P., Eggermann, E., Cauli, B., Mu, M., 2000. Identication of sleeppromoting neurons in vitro. Nature 404, 3-6.

Gallopin, T., Luppi, P.H., Cauli, B., Urade, Y., Rossier, J., Hayaishi, O., Lambolez, B., Fort, P., 2005. The endogenous somnogen adenosine excites a subset of sleeppromoting neurons via $\mathrm{A} 2 \mathrm{~A}$ receptors in the ventrolateral preoptic nucleus. Neuroscience 134, 1377-1390.

Gaus, S.E., Strecker, R.E., Tate, B.A., Parker, R.A., Saper, C.B., 2002. Ventrolateral preoptic nucleus contains sleep-active, galaninergic neurons in multiple mammalian species. Neuroscience 115, 285-294.

Gong, H., McGinty, D., Guzman-Marin, R., Chew, K.-T., Stewart, D., Szymusiak, R., 
2004. Activation of c-fos in GABAergic neurones in the preoptic area during sleep and in response to sleep deprivation. J. Physiol. 556, 935-46.

Gong, H., Szymusiak, R., King, J., Steininger, T., McGinty, D., 2000. Sleep-related cFos protein expression in the preoptic hypothalamus: effects of ambient warming. Am. J. Physiol. Regul. Integr. Comp. Physiol. 279, R2079-88.

Gong, S., Zheng, C., Doughty, M.L., Losos, K., Didkovsky, N., Schambra, U.B., Nowak, N.J., Joyner, A., Leblanc, G., Hatten, M.E., Heintz, N., 2003. A gene expression atlas of the central nervous system based on bacterial artificial chromosomes. Nature $425,917-25$.

Greco, M.-A., Fuller, P.M., Jhou, T.C., Martin-Schild, S., Zadina, J.E., Hu, Z., Shiromani, P., Lu, J., 2008. Opioidergic projections to sleep-active neurons in the ventrolateral preoptic nucleus. Brain Res. 1245, 96-107.

Gritti, I., Mainville, L., Jones, B.E., 1993. Codistribution of GABA- with acetylcholinesynthesizing neurons in the basal forebrain of the rat. J. Comp. Neurol. 329, 43857.

Hajós, M., Gartside, S.E., Varga, V., Sharp, T., 2003. In vivo inhibition of neuronal activity in the rat ventromedial prefrontal cortex by midbrain-raphe nuclei: Role of 5-HT1A receptors. Neuropharmacology 45, 72-81.

Hannon, J., Hoyer, D., 2008. Molecular biology of 5-HT receptors. Behav. Brain Res. $195,198-213$.

Imeri, L., Bianchi, S., Opp, M.R., 2005. Antagonism of corticotropin-releasing hormone alters serotonergic-induced changes in brain temperature, but not sleep, of rats. Am. J. Physiol. Regul. Integr. Comp. Physiol. 289, R1116-23.

Imeri, L., Mancia, M., Bianchi, S., Opp, M.R., 1999. 5-hydroxytryptophan, but not Ltryptophan, alters sleep and brain temperature in rats. Neuroscience 95, 445-452.

Johnston, A., McBain, C.J., Fisahn, A., 2014. 5-Hydroxytryptamine1A receptoractivation hyperpolarizes pyramidal cells and suppresses hippocampal gamma oscillations via Kir3 channel activation. J. Physiol. 592, 4187-99.

Jouvet, M., 1999. Sleep and serotonin: an unfinished story. Neuropsychopharmacology 
$21,24 \mathrm{~S}-27 \mathrm{~S}$.

Jouvet, M., Renault, J., 1966. [Persistence of insomnia after lesions of the nuclei of the raphe in the cat]. C. R. Seances Soc. Biol. Fil. 160, 1461-5.

Kantor, S., Jakus, R., Balogh, B., Benko, A., Bagdy, G., 2004. Increased wakefulness, motor activity and decreased theta activity after blockade of the 5-HT2B receptor by the subtype-selective antagonist SB-215505. Br. J. Pharmacol. 142, 1332-42.

Karagiannis, A., Gallopin, T., David, C., Battaglia, D., Geoffroy, H., Rossier, J., Hillman, E.M., Staiger, J.F., Cauli, B., 2009. Classification of NPY-expressing neocortical interneurons. J Neurosci 29, 3642-3659.

Lamigeon, C., Bellier, J.P., Sacchettoni, S., Rujano, M., Jacquemont, B., 2001. Enhanced neuronal protection from oxidative stress by coculture with glutamic acid decarboxylase-expressing astrocytes. J. Neurochem. 77, 598-606.

Lin, S.L., Setya, S., Johnson-Farley, N.N., Cowen, D.S., 2002. Differential coupling of 5-HT(1) receptors to G proteins of the G(i) family. Br. J. Pharmacol. 136, 10721078.

Liu, Y.-W., Zuo, W., Ye, J.-H., 2013. Propofol stimulates noradrenalin-inhibited neurons in the ventrolateral preoptic nucleus by reducing GABAergic inhibition. Anesth. Analg. 117, 358-63.

Lu, J., Bjorkum, A.A., Xu, M., Gaus, S.E., Shiromani, P.J., Saper, C.B., 2002. Selective activation of the extended ventrolateral preoptic nucleus during rapid eye movement sleep. J Neurosci 22, 4568-4576.

Lu, J., Greco, M.A., Shiromani, P., Saper, C.B., 2000. Effect of lesions of the ventrolateral preoptic nucleus on NREM and REM sleep. J Neurosci 20, 3830-3842.

McGinty, D.J., Harper, R.M., 1976. Dorsal raphe neurons: depression of firing during sleep in cats. Brain Res. 101, 569-575.

Monti, J.M., 2011. Serotonin control of sleep-wake behavior. Sleep Med.Rev. 15, 269281.

Moore, J.T., Chen, J., Han, B., Meng, Q.C., Veasey, S.C., Beck, S.G., Kelz, M.B., 2012. Direct activation of sleep-promoting VLPO neurons by volatile anesthetics 
contributes to anesthetic hypnosis. Curr. Biol. 22, 2008-16.

Morrow, J.D., Vikraman, S., Imeri, L., Opp, M.R., 2008. Effects of serotonergic activation by 5 -hydroxytryptophan on sleep and body temperature of C57BL/6J and interleukin-6-deficient mice are dose and time related. Sleep 31, 21-33.

Pinal, C.S., Tobin, A.J., 1998. Uniqueness and redundancy in GABA production. Perspect. Dev. Neurobiol. 5, 109-18.

Portas, C.M., McCarley, R.W., 1994. Behavioral state-related changes of extracellular serotonin concentration in the dorsal raphe nucleus: A microdialysis study in the freely moving cat. Brain Res. 648, 306-312.

Python, A., Steimer, T., De Saint Hilaire, Z., Mikolajewski, R., Nicolaidis, S., 2001. Extracellular serotonin variations during vigilance states in the preoptic area of rats: A microdialysis study. Brain Res. 910, 49-54.

Saint-Mleux, B., Eggermann, E., Bisetti, A., Bayer, L., Machard, D., Jones, B.E., Mühlethaler, M., Serafin, M., 2004. Nicotinic enhancement of the noradrenergic inhibition of sleep-promoting neurons in the ventrolateral preoptic area. J. Neurosci. 24, 63-67.

Sakai, K., Crochet, S., 2001. Differentiation of presumed serotonergic dorsal raphe neurons in relation to behavior and wake-sleep states. Neuroscience 104, 11411155.

Saper, C.B., Chou, T.C., Scammell, T.E., 2001. The sleep switch: hypothalamic control of sleep and wakefulness. Trends Neurosci. 24, 726-31.

Scharbarg, E., Daenens, M., Lemaître, F., Geoffroy, H., Guille-Collignon, M., Gallopin, T., Rancillac, A., 2016. Astrocyte-derived adenosine is central to the hypnogenic effect of glucose. Sci. Rep. 6, 19107.

Sherin, J.E., Elmquist, J.K., Torrealba, F., Saper, C.B., 1998. Innervation of histaminergic tuberomammillary neurons by GABAergic and galaninergic neurons in the ventrolateral preoptic nucleus of the rat. J Neurosci 18, 4705-4721.

Sherin, J.E., Shiromani, P.J., McCarley, R.W., Saper, C.B., 1996. Activation of ventrolateral preoptic neurons during sleep. Science 271, 216-9. 
Soghomonian, J.J., Martin, D.L., 1998. Two isoforms of glutamate decarboxylase: why? Trends Pharmacol. Sci. 19, 500-5.

Steininger, T.L., Gong, H., McGinty, D., Szymusiak, R., 2001. Subregional organization of preoptic area/anterior hypothalamic projections to arousal-related monoaminergic cell groups. J. Comp. Neurol. 429, 638-53.

Stiedl, O., Pappa, E., Konradsson-Geuken, Å., Ögren, S.O., 2015. The role of the serotonin receptor subtypes 5-HT1A and 5-HT7 and its interaction in emotional learning and memory. Front. Pharmacol. 6, 162.

Szymusiak, R., Alam, N., Steininger, T.L., McGinty, D., 1998. Sleep-waking discharge patterns of ventrolateral preoptic/anterior hypothalamic neurons in rats. Brain Res. $803,178-88$.

Trulson, M.E., Jacobs, B.L., 1979. Raphe unit activity in freely moving cats: correlation with level of behavioral arousal. Brain Res. 163, 135-150.

Uschakov, A., Gong, H., McGinty, D., Szymusiak, R., 2007. Efferent projections from the median preoptic nucleus to sleep- and arousal-regulatory nuclei in the rat brain. Neuroscience 150, 104-20.

Uschakov, A., Gong, H., McGinty, D., Szymusiak, R., 2006. Sleep-active neurons in the preoptic area project to the hypothalamic paraventricular nucleus and perifornical lateral hypothalamus. Eur. J. Neurosci. 23, 3284-3296.

Valatx, J.L., 1996. [Mechanisms of dream-sleep-wakefulness cycle]. Rev. Prat. 46, 240410.

Varin, C., Rancillac, A., Geoffroy, H., Arthaud, S., Fort, P., Gallopin, T., 2015. Glucose Induces Slow-Wave Sleep by Exciting the Sleep-Promoting Neurons in the Ventrolateral Preoptic Nucleus: A New Link between Sleep and Metabolism. J. Neurosci. 35, 9900-11.

Volk, D.W., Austin, M.C., Pierri, J.N., Sampson, A.R., Lewis, D.A., 2000. Decreased glutamic acid decarboxylase67 messenger RNA expression in a subset of prefrontal cortical gamma-aminobutyric acid neurons in subjects with schizophrenia. Arch. Gen. Psychiatry 57, 237-45. 
Vucurovic, K., Gallopin, T., Ferezou, I., Rancillac, A., Chameau, P., van Hooft, J.A., Geoffroy, H., Monyer, H., Rossier, J., Vitalis, T., 2010. Serotonin 3A receptor subtype as an early and protracted marker of cortical interneuron subpopulations. Cereb Cortex 20, 2333-2347.

Waagepetersen, H.S., Sonnewald, U., Schousboe, A., 1999. The GABA paradox: multiple roles as metabolite, neurotransmitter, and neurodifferentiative agent. J. Neurochem. 73, 1335-42. 


\section{Figures and legends}

A
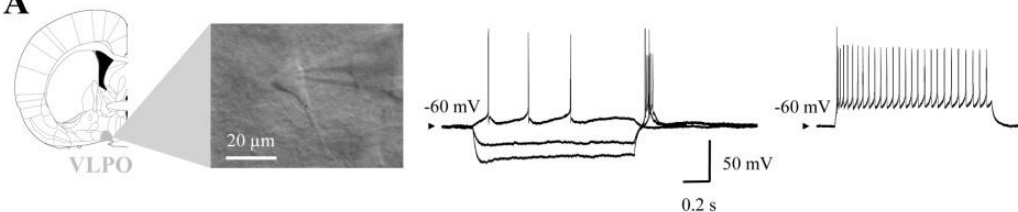

B

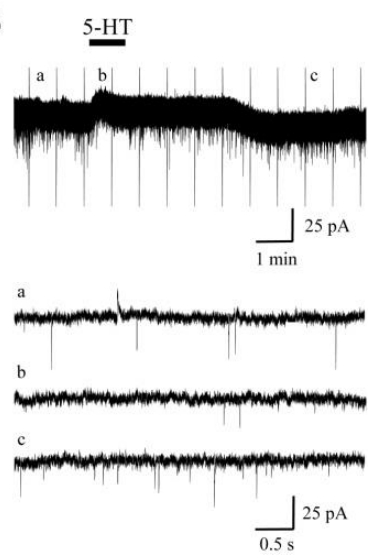

$\mathbf{E}$
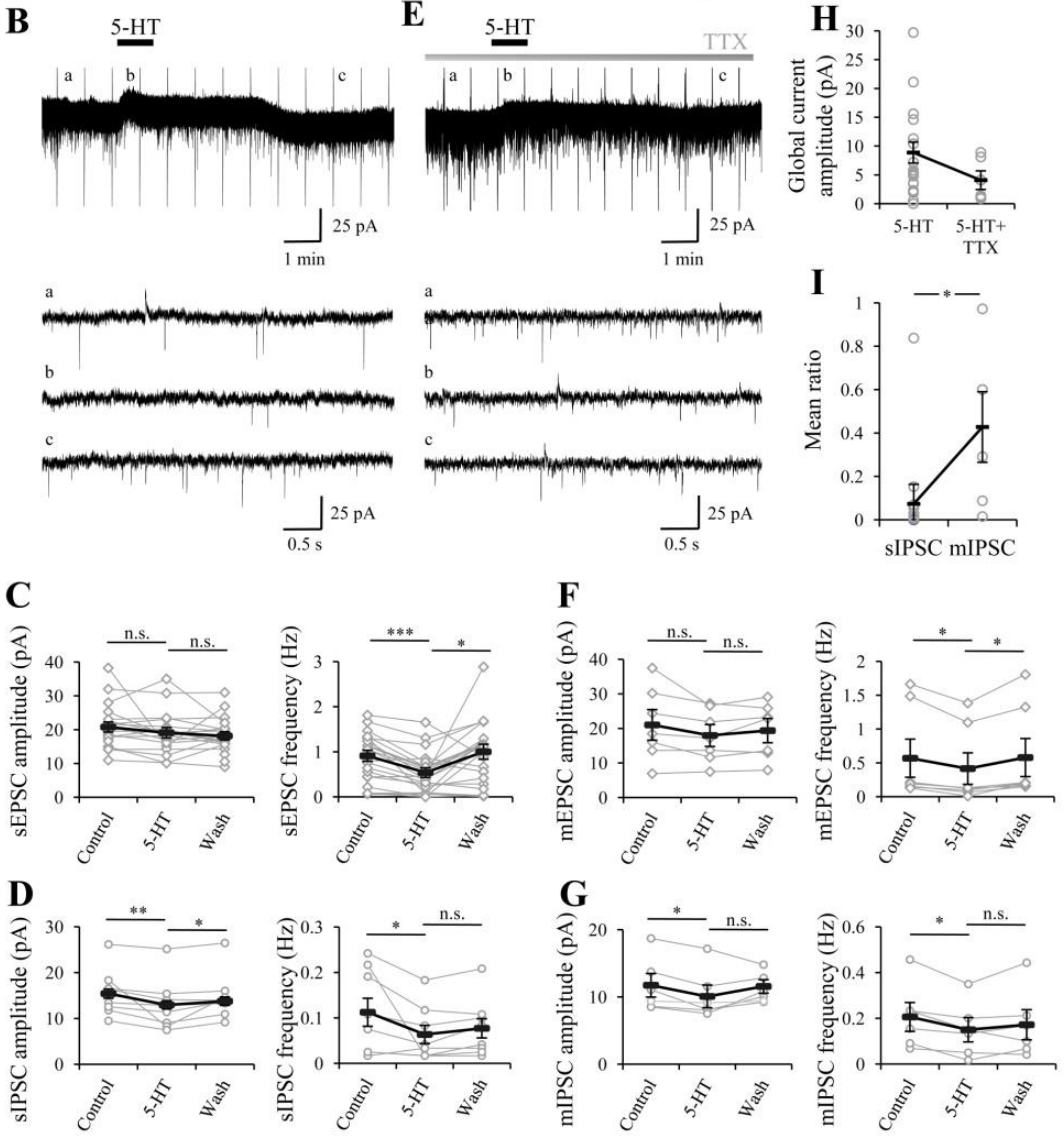

Figure 1. 5-HT decreases the frequency of excitatory and inhibitory synaptic inputs to Type-1 PSP neurons and reduces the amplitude of inhibitory inputs. (A) Infrared image of a Type-1 PSP neuron within the VLPO (left panel). The electrophysiological behavior of the neuron was recorded in current-clamp mode in response to current pulse injections $(-100 \mathrm{pA} ;-50 \mathrm{pA} ; 10 \mathrm{pA}$; middle panel). Application of a larger depolarizing current ( $200 \mathrm{pA}$, prior to the saturated response) induced a response with a marked frequency adaptation and a high firing frequency (right panel). (B) Whole-cell recording in voltage-clamp configuration of the global response to 5-HT application (100 $\mu \mathrm{M}$ for $1 \mathrm{~min}$; top panel). Holding potential was $-60 \mathrm{mV}$. The letters $\mathrm{a}, \mathrm{b}$ and $\mathrm{c}$ correspond to the higher magnifications illustrated in the lower panels. (C and D) Summary of the 5-HT effect on excitatory (diamonds, $n=19$; C) and inhibitory (circles, $n=8$; D) PSCs in all recorded PSP Type-1 neurons. Effects on amplitude are shown on the left side of each panel, whereas effects on frequency are illustrated on the right. Empty symbols represent values from individual cells, and solid bars denote average values. (E-G) Experiments were performed similarly to B-D, but in the presence of TTX $(1 \mu \mathrm{M} ; n=7$ in F and $n=6$ in $\mathrm{G})$. (H) Histogram of the mean global current induced by 5-HT application $(100 \mu \mathrm{M}$ for $1 \mathrm{~min})$ in the absence $(n=19)$ or presence of TTX $(n=7)$. (I) Histogram for the ratio of mean sIPSCs $(n=19)$ and mIPSCs $(n=7)$, in the presence of 5-HT. Wilcoxon test; $* P \leq 0.05$; $* * P \leq 0.01 ; * * * P \leq 0.001$. Note that only 8 out of 19 neurons exhibited sIPSCs. 5 -HT effects in the presence of TTX were preferentially tested on neurons showing both mEPSCs and mIPSCs. 
A
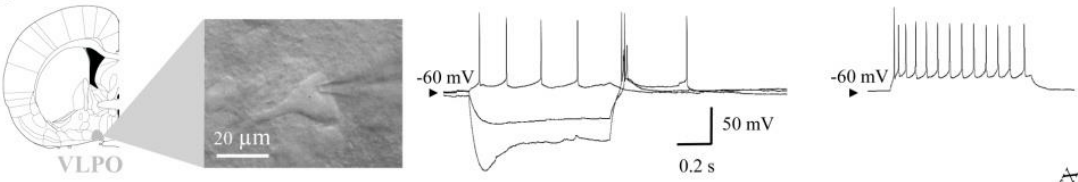

B

E
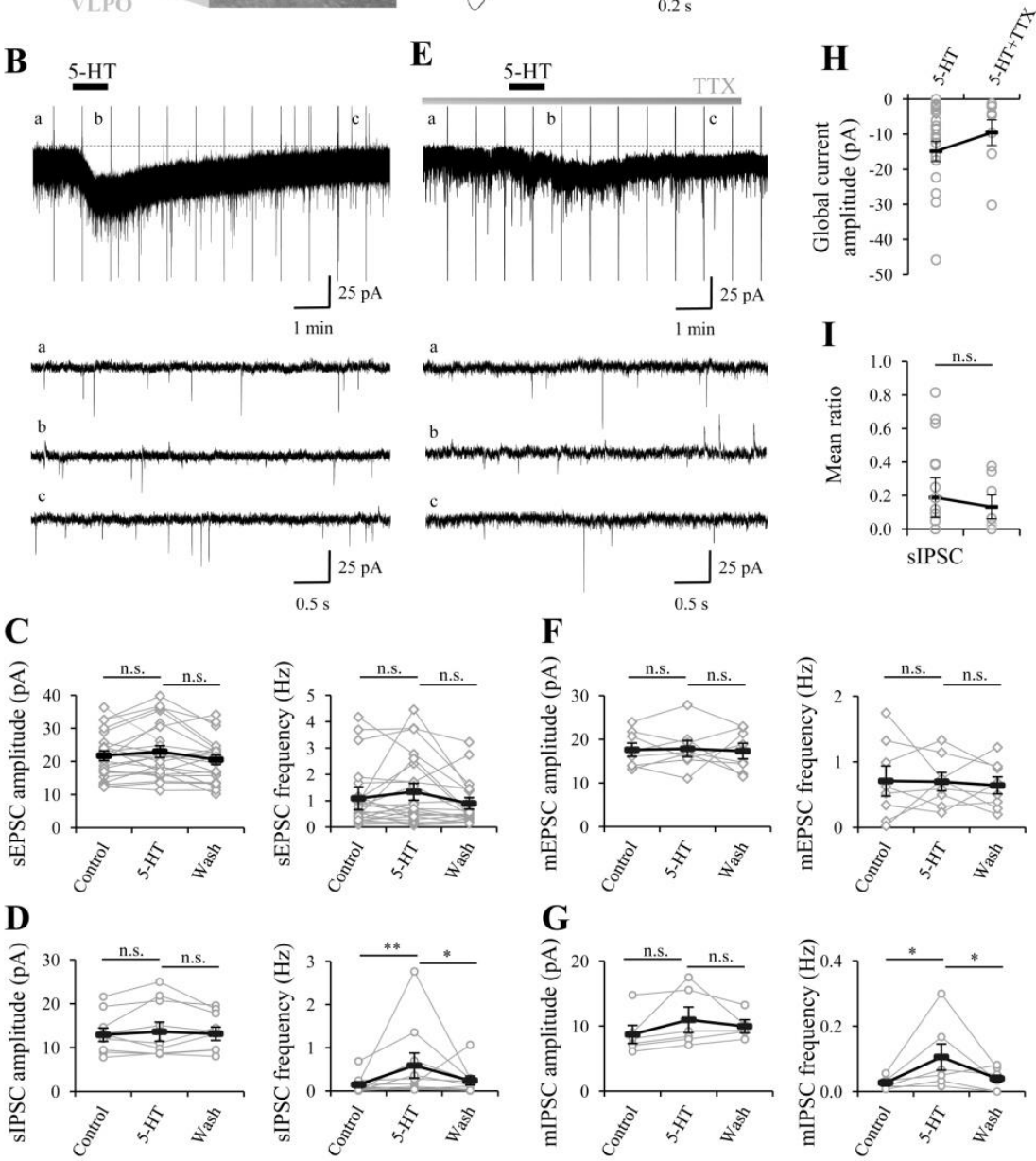

Figure 2. 5-HT selectively increases the frequency of inhibitory synaptic inputs to Type-2 PSP neurons. (A) Infrared image of a Type-2 PSP neuron within the VLPO (left panel). The electrophysiological behavior of the neuron was recorded in current-clamp mode, in response to current pulse injections $(-100 \mathrm{pA} ;-50 \mathrm{pA} ; 10 \mathrm{pA}$; middle panel). Application of a larger depolarizing current $(70 \mathrm{pA}$, prior to the saturated response) induced a non-adapting response with a low firing frequency (right panel). (B) Whole-cell recording in voltage-clamp configuration of the global response to 5-HT application ( $100 \mu \mathrm{M}$ for $1 \mathrm{~min}$; top panel). Holding potential was $-60 \mathrm{mV}$. The letters $\mathrm{a}, \mathrm{b}$ and $\mathrm{c}$ correspond to the higher magnifications illustrated in the lower panels. (C and D) Summary of the 5-HT effect on excitatory (diamonds, $n=23$; C) and inhibitory (circles, $n=10$; D) PSCs in all recorded PSP Type-2 neurons. Effects on amplitude are shown on the left side of each panel, whereas effects on frequency are illustrated on the right. Empty symbols represent values from individual cells, and solid bars denote average values. (E-G) Experiments were performed similarly to panels B-D, but in the presence of TTX $(1 \mu \mathrm{M} ; n=8$ in $F$ and $n=6$ in $\mathrm{G}$ ). (H) Histogram of the mean global current induced by 5-HT application $(100 \mu \mathrm{M}$ for $1 \mathrm{~min})$ in the absence $(n=23)$ or presence of TTX $(n=8)$. (I) Histogram for the ratio of mean sIPSCs $(n=23)$ and mIPSCs $(n=8)$, in the presence of 5-HT. Wilcoxon test; $* P \leq 0.05$; $* * P \leq 0.01$. Note that only 10 out of 23 neurons exhibited sIPSCs. 5-HT effects in the presence of TTX were preferentially tested on neurons showing both mEPSCs and mIPSCs. 
A
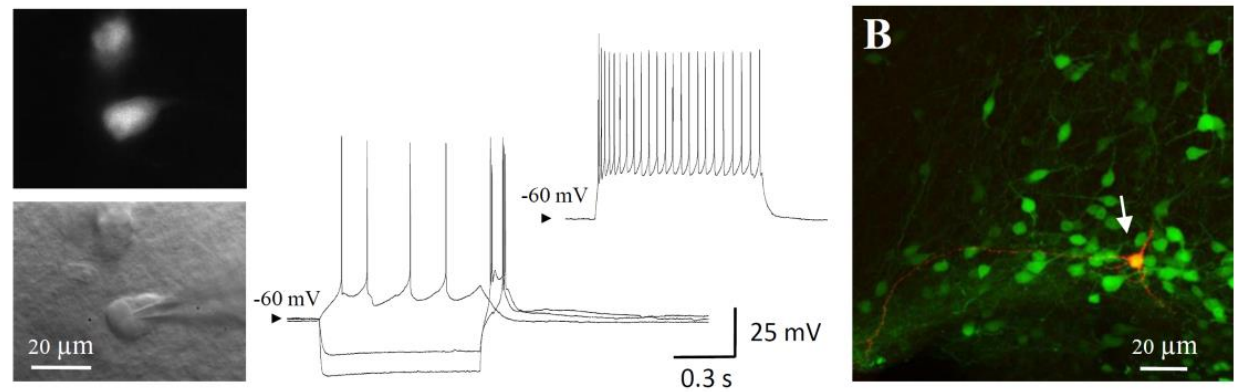

C

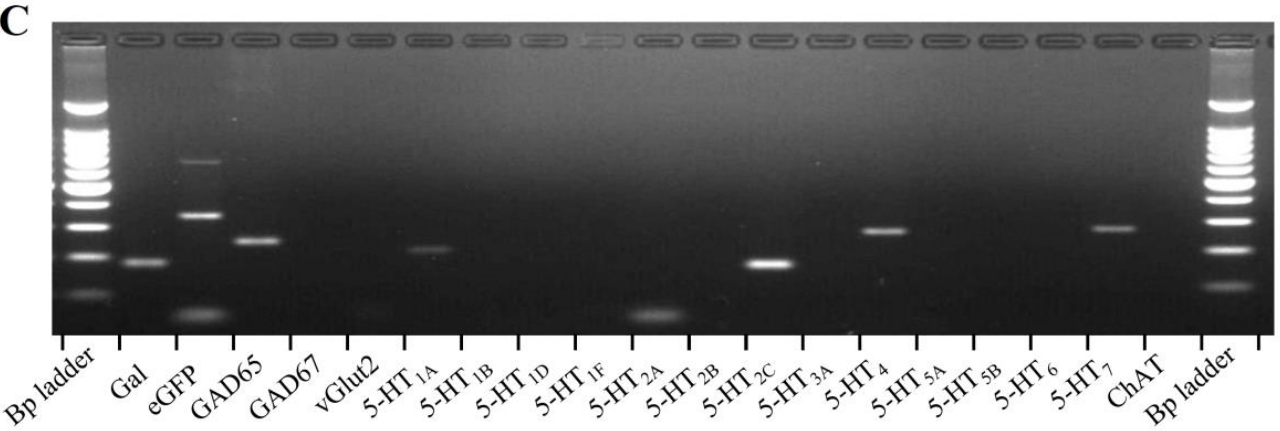

D

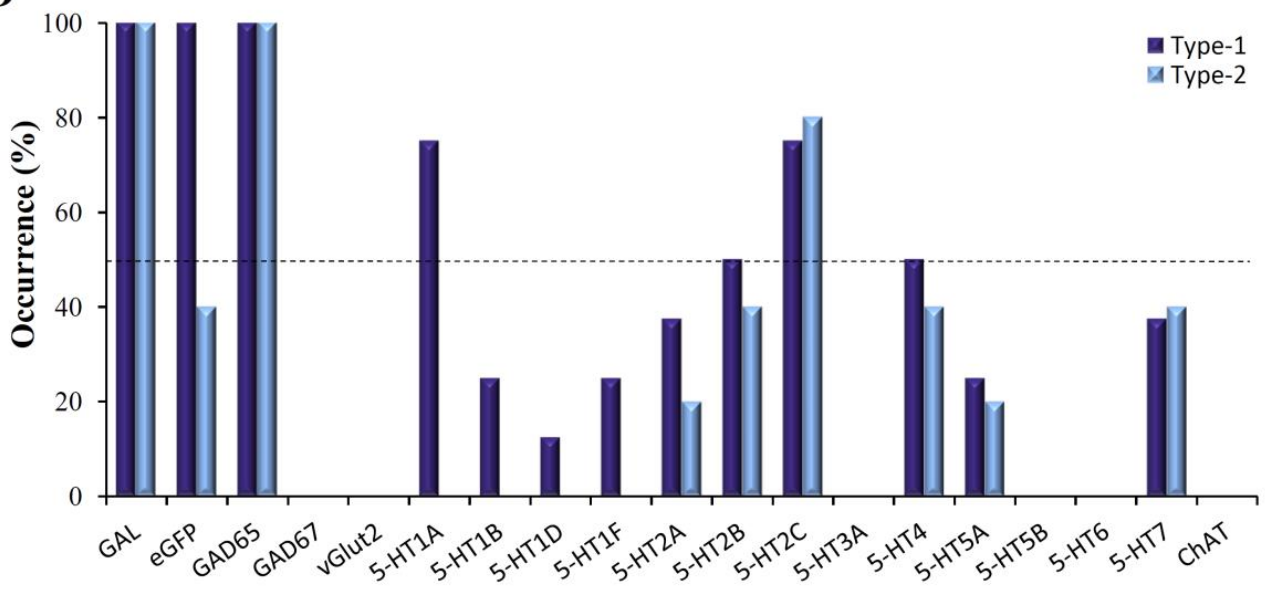

Figure 3. Electrophysiological and molecular properties of Gal-GFP neurons in the VLPO. (A) The electrophysiological behavior of a Type-1 neuron recorded using wholecell patch-clamp recording in current-clamp mode, in response to current pulses. Responses at subthreshold and just above threshold are illustrated (-100, -50 and $10 \mathrm{pA}$ current injection). Current injection just above threshold induced an adapting firing of action potential frequency. The panel on the right shows that application of a larger depolarizing current (120 pA) induced a marked frequency adaptation. Epifluorescence and infrared images of the same neuron were taken prior to recording (left panels). (B) Confocal image of a Gal-GFP neuron (biocytin labeling: red) immunoreactive for GFP (GFP: green). Note the density of neighboring fluorescent neurons present in the core of the VLPO. (C) Agarose gel of a representative 5-HT (-) neuron showing the expression of Gal, GFP, GAD65, 5-HT1A, 5-HT2C, 5-HT4 and 5-HT7. Bp ladder: 100 bp molecular weight marker for indicating relative molecular mass. (D) Summary of the scRT-PCR analysis of Type-1 $(n=8)$ and Type-2 $(n=5)$ Gal-GFP neurons. 

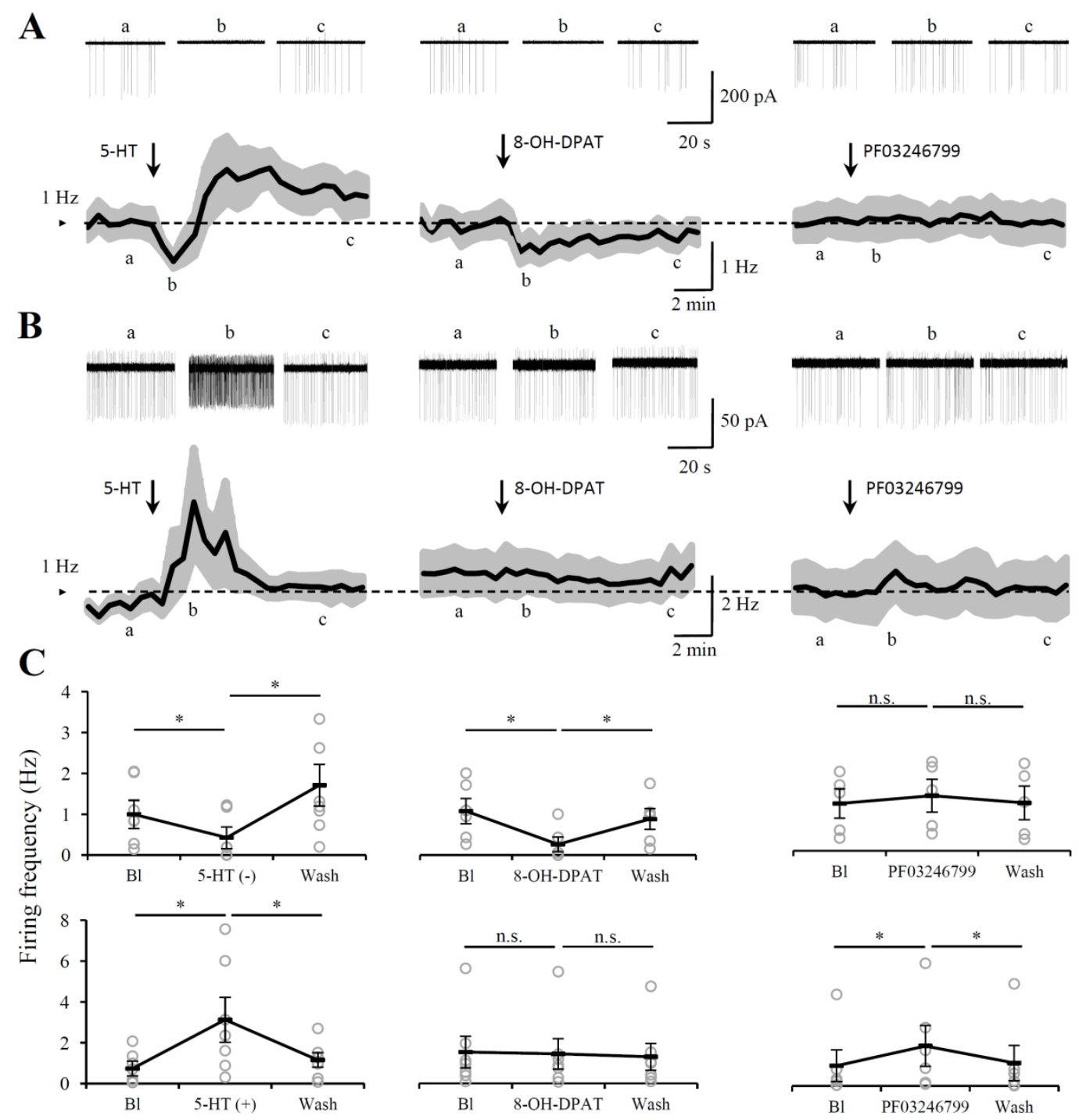

Figure 4. Effects of 5-HT, 8-OH-DPAT, and PF03246799 on the spontaneous firing rate of VLPO Gal-GFP neurons, recorded in loose cell-attached configuration. (A) Typical recording of a single neuron during the baseline period (a), at the peak of the effect (b) and at the end of the wash (c) are illustrated in the upper panels. Mean firing rates are represented in the lower panels (black line) surrounded by the SEM (gray area). 5-HT $(100 \mu \mathrm{M}, 5 \mathrm{~s})$ decreased the firing rate of Type-1 neurons $(n=7)$. This inhibition was reproduced by bath application of 8-OH-DPAT $(1 \mu \mathrm{M}, 20 \mathrm{~s})$, a 5-HT $\mathrm{HA}_{1 \mathrm{~A}}$ receptor agonist in 6 out of the 75 -HT (-) neurons. On the opposite, PF03246799 $(10 \mu \mathrm{M}, 20 \mathrm{~s})$, a 5-HT $2 \mathrm{c}$ receptor agonist, induced a slight increased of their firing rate $(n=5)$. (B) In 5-HT (+) neurons, bath application of 8-OH-DPAT had no effect $(n=7)$ and PF03246799 increased the firing rate $(n=6)$. (C) Summary of the 5-HT, 8-OH-DPAT, and PF03246799 effects shown in A and B, on Type-1 neurons (top traces) and Type-2 PSP neurons (bottom traces). Wilcoxon test; $* P \leq 0.05$. 